\title{
Ülkemizde Kadın Karikatüristler
}

\author{
Akif Seven
}

\author{
Biz çizgi overlokçular... \\ hayal bohçacıları...mürekkep cinleri... \\ gül ekicileri...yel biçicileri...
}

\begin{abstract}
$\ddot{O} z$
Bu araştırmanın amacl, tarihin belirli dönemlerinde ruhani bir varlık olarak saygl gösterilen kadının, ülkemizdeki karikatür sanatındaki yerini ve kadın karikatüristlerin sanatçı kişiliğ̈ini irdeleyip, tarihsel süreç içerisinde durumunu ortaya koymaktır. İnsanoğlunun ilk ortaya çıtktı̆̆ andan itibaren bütün toplumlarda kadın vazgeçilmez bir unsur olarak karşımıza çıkmaktadır. Gerek dinsel konulu tasvirlerde gerekse de günlük doğal yaşamından sahnelerin tasvirinde çokça kullanılmıştır. Kadın ilk çağlarda kimi zaman bereket kimi zaman tanrısal güç, kimi zaman da ideal güzellik sembolü olarak betimlenmiştir. Değişik dönemlerde yaşamış olan sanatçılar, kadını, güzelliği sembolize eden bir değer olarak görmüş ve eserlerine aktarmıştır. Ailede ve toplumda önemli bir yere sahip olan ve birçok sanat eserine sahip olan kadınlar genellikle erkek sanatçılar tarafindan ele alınmıştır. Buna en iyi örnek ideal güzelliği sembolize eden vegeniş bir kitle tarafindan bilinen, Leonardo Da Vinci'nin Mona Lisa 'sıdır.

Toplumda bu kadar önemli bir yere sahip olanve birçok sanatçı tarafindan ele alınan kadının, sanatı üretme noktasında yeterli düzeyde karşımıza çıkmadığı görülmektedir. Aynı durum bir abartma sanatı olan karikatür sanatı için de geçerlidir.
\end{abstract}

Anahtar Sözcükler: Sanat, Mizah, Karikatür, Kadın

\section{Female Cartoonists in Our Country}

\begin{abstract}
Theaim of this research is to investigate the artistic personality and the place of female cartoonists in our country who were historically respected as a spiritual being and is to bring up their situation in historical process. Through the existence of human beings, a lady appears as an indispensable fact in all societies. She has been frequently used both on religious description sand the descriptions of the Daily natural life's scenes. Through the early ages, a lady is described sometimes as the symbol of fertility sometimes as a celestial power or the symbol of the ideal beautyby her figure in similar contextand similar themes. The artists who lived in different periods regarded a lady as a merit who symbolizes beauty and they transferred her in their works. Women who have. An important place both in family and society and have manyart Works are generally handled by maleartists. The best example for this thesisis Mona Lisa by Leonardo Da Vinci which symbolizes ideal beauty and which is widely known by community.

Although she has an important place in society and is handled by many artists, a lady does not appear enough when it comes to produce art works. The situation is the same as the cartoon art which is an art of exaggeration.
\end{abstract}

Keywords: Art, Humour, Cartoons, Female 


\section{Giriş}

Sanat; sese, söze, maddeye, hacme, renk, çizgi ve yüzeye, hoşa giden bağlantıları bulunan, ahenkli biçimler vermek ya da vermeye çalışmaktır. İnsanın duygu, düşünce ve heyecanlarının, ruhsal deneylerinin başkalarına aktarılabilmesi, yani duygu ve düşüncelerin biçimlendirilmesi olarak da tanımlanabilir (Yolcu, 2004, s.9).

Bilinen en eski sanat eseri Güney Afrika'nın Güney Kap Burnu kıyısındaki Blombos Mağarası'nda bulunan ve 77.000 yıl öncesine dayanan kazıma olarak işlenmiş iki küçük okr çubuğudur. Bilinen en eski mağara resimleri ise M.Ö.30.000 yılına uzanır. Bu resimler gizemini korusa da dinsel ve büyüsel amaçlarla yapıldıkları tahmin edilmektedir (Farthing, 2012, s.17)

Sanat tarihi açısından ilginç olan ise 7 Temmuz 2009 tarihli Milliyet Gazetesi'nin arka sayfasında yer alan 'Mağara resimlerini dişi kuşlar yapmış' başlıklı haberdir. ABD'deki Pennsylvania Üniversitesi arkeologlarından Profesör Dean Snow, Fransa' daki PechMerle ve Gargas, mağaralarının duvarlarında bulunan el izleri üzerinde yapılan analizlerin pek çoğunun kadınlara ait olduğunu ortaya koymuştur. Prof. Snow tarih öncesi kadın sanatçıların, aynı zamanda ünlü "Benekli Atlar" adlı mağara resimlerinin yapımına da yardım ettiklerini belirtmiştir. Prof. Snow'a göre günümüz insanının el oranları ile mağara duvarlarında yer alan el izlerinin oranlarını karşılaştırıldığında tarih öncesi devirlerde kadının toplum içindeki rolünün zannedildiğinden çok daha büyük olduğu görülmektedir. Snow, "Geç taş devrinde sanatçıların toplumdaki rolünü bilmiyoruz. Ancak genel olarak çoğunluğu kadınların oluşturduğunu söyleyebiliriz” demiştir.

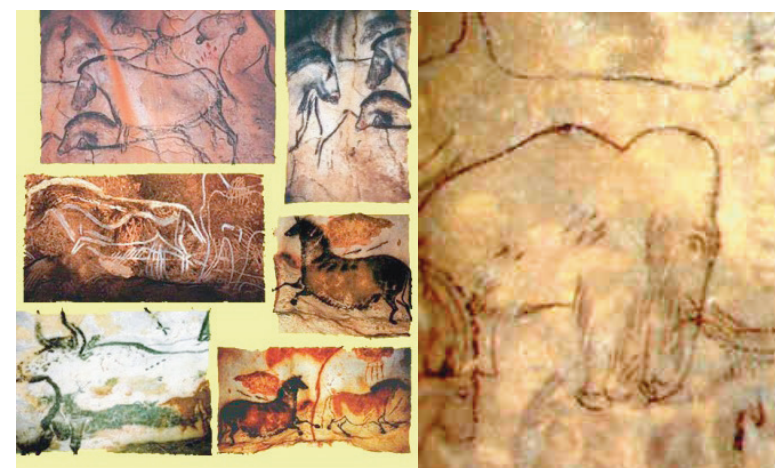

Birçok kesime göre kadınlar iyi ressam değillerdir. Oysaki yukarıda ortaya konulmuş olan araştırmada sanatın tarihinin kadın ile başladığı söylenebilir. Dünya resim sanatı tarihine bakıldığında ise çok fazla kadın ressam ile karşılaşılmamaktadır (Aktaran, Ulusoy, 1999, s.52). Aynı sonuçları mizah yapan, karikatür çizen kadınlarda da görmek mümkündür.

Ülkemizde mizah sözcüğüne karşılık olarak kullanılan humour Fransızca’ dan gelmektedir. Humour hem yazı hem de çizgi ile olabilir. Humour, gerçeğin en hoş ya da en özgür bir biçimde tasarlamaya ve sunmaya yönelik ruh durumu anlamına geldiği gibi gülünçlükleri ve gerçeğin tuhaflıklarını vurgulamaya dayanan hoş bir alay biçimi olarak da tanımlanabilir (Topuz, 1997, s.9).

Karikatür çizgi ile yapılan mizahtır. İçerisinde gülme ögesi bulunan; aynı zamanda iğneleyici, uyarıc1, eleştiren, toplumdaki çelişkileri yakalayan güldüren bir yandan düşündüren bir sanattır (Özer,1994, s.2). Karikatür içinde taşıdığı üç öge ile diğer sanatlardan farklılık gösterir. Bu üç öğe: Çizgi, Mizah, Düşünce'dir (Akt.Uslu, 2007, s.36). 


\section{Kadın Karikatüristler}

Profesyonel anlamda değerlendirilen kadın karikatür sanatçı sayısı sanat tarihi literatürlerinde hâlâ çok azdır. Aynı durum Türk karikatür sanatında da görülmektedir. Semih Balcığlu tarafindan hazırlanan 75. Yılında Türk Karikatür Sanatı kitabında 121 karikatüristin adı geçmektedir. Bunlardan sadece 7 tanesi kadın karikatüristtir. Bunun yanında kadın eserleri kütüphanesi ve bilgi merkezi vakfı tarafından hazırlanan 2007 yılı Kadın ve Mizah: Kadın Karikatüristler Ajandası'nda ise 28 kadın karikatüristin adı geçmektedir.

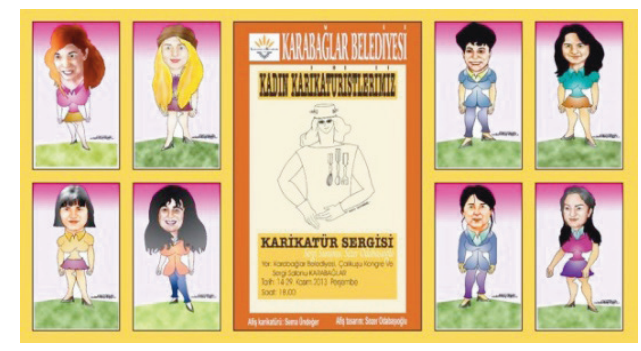

\section{Sezer Odabaşoğlu. Kadın Karikatüristlerimiz Afişi}

Kadın karikatüristler ile ilgili en geniş kapsamlı çalışmayı karikatürist Sezer Odabaşığlu yapmaktadır. Bir sosyal paylaşım sitesi üzerinden yapılan görüşmede, Odabaşı 102 kadın karikatüristin ismine ulaştı̆̆ını, bunlardan 73 tanesinin karikatürüne ve özgeçmişinin elinde olduğunu belirtmiştir. Odabaşoğlu karikatür ve özgeçmişine ulaştığı kadın karikatüristler ile ilgili 14-29 Kasım 2013 tarihleri arasında İzmir / Karabağlar Belediyesi Çalıkuşu Kongre ve Sergi Salonu’nda bir sergi açmıştır. Odabaşoğlu, sergide adı geçen kadın karikatüristlerden oluşan bir kitap hazırlamaktadır.

Bizde ilk kadın karikatürcü 1908-1918 Meşruiyet Dönemi’nde Leylâk dergisinde görülür. Çizerleri arasında Fatma Zehra Hanım vardır. Turgut Çeviker, "Leylâk, bir kadın gazetesidir, denebilir. Belki de kadınlar için mizah.” der (Çeviker,1988, s.202). Kadınlar için hazırlanmış Fatma Zehra Hanım'ın ilk mizah dergisi Leylâk’ta çizdiği bir karikatür şu şekildedir:

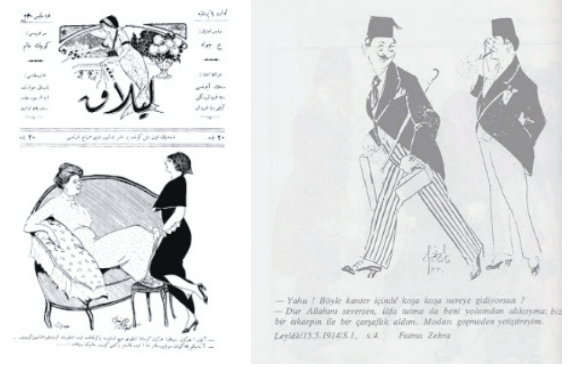

Osmanlı döneminde çizmiş ikinci bir kadın karikatürcüye rastlanılmamıştır. Fakat Cumhuriyet dönemi için durum değişti. 1930 ve 1940`larda Cumhuriyet ve Tan gazeteleriyle Şaka ve Akbaba mizah dergilerinde Melilâ Fuat imzası, kimi karikatürlerde göze çarpmaktadır. Döneminde tanınmış - ancak bugün hiçbir sanat sözlüğünde yer verilmemiş- ressamlardan olan Bayan Fuat'ın, süreli yayınlarda birçok karikatürüne rastlanılmaktadır (Çeviker, 2013,http://www.sahirabaci.com/ sahirabaci/pages/posts/kadin-mizah-40.php).

Daha sonraki dönemlerde kadın temalı çalışmalar artsa da kadın karikatürcü görülmemektedir. 1920’de Sedat Simavi’nin “Kadınlar Saltanatı” adlı ikinci albümü çıkmıştır. Ramiz Gökçe 1945 'te 
Kadınlar Albümü' nü yayımlamıştır. 1946'da da Tombul Teyze görülmektedir (Çeviker,1988:c;3 63-106). 2. Dünya Savaşı döneminde 1928 İstanbul doğumlu Selma Emiroğlu (Aykan) 14 yaşında Amcabey dergisinde ilk karikatürlerini yayımlamıştır (Balcığlu,1983:133). Emiroğlu, Amcabey ile başlayan çizgi yaşamını Doğan Kardeş, Tef, Akbaba dergilerinde sürdürür. Daha sonra Almanya’ya yerleşir.

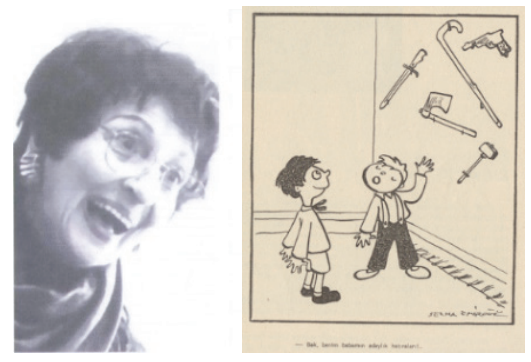

Selma Emiroğlu

Selma Emiroğlu'ndan bir karikatür

Kadın karikatürcüler 1950'li ve daha sonraki yıllarda öne çıksalar da beklenilenin çok altında kalmaktadır. Bu çizerler; Selma Gündüz, Meral Simer, Semiramis Aydınlık, Sema Ündeğer gibi kadın karikatürcülerdir.

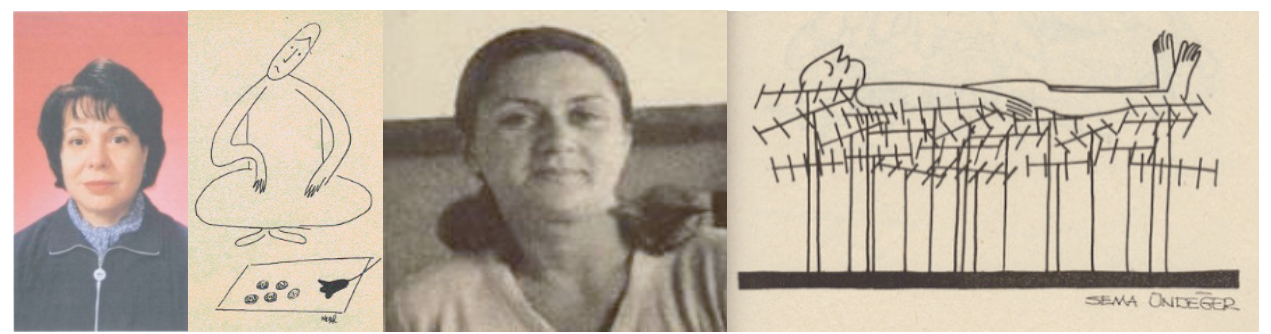

Meral Simer'in bir karikatürü ve Selma Ündeğer'in bir karikatür

1972’de Gırgır'ın çıkışıyla kadınların karikatüre ilgisi artar. 6-7 yıl sonra Oğuz Aral genç çizerlere dergide yer verince Özden Öğrük, Gülay Batur, Ramize Erer, Meral Onat ve Eda Oral "Biz Bıyıksızlar” köşesinde kadınların sorunlarını ve yaşamlarını dile getiren karikatürlere yer verirler.

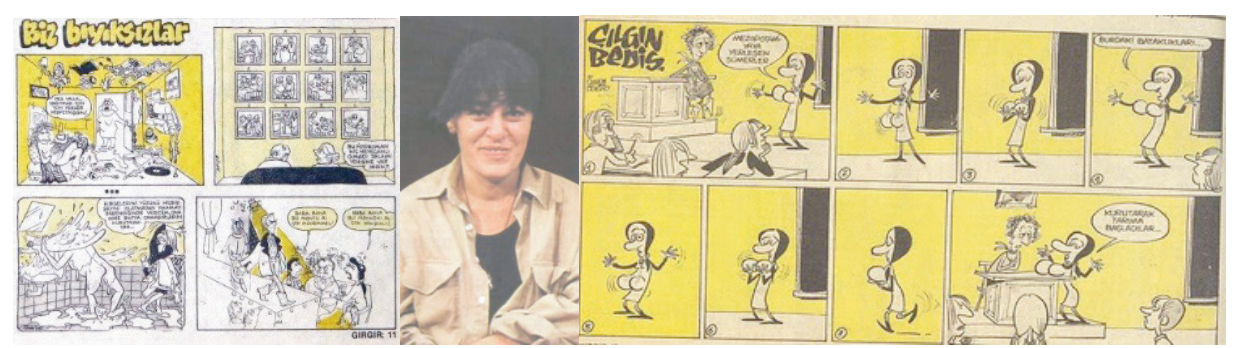

Biz Bıyıksızlar Özden Öğrük’ten Çılgın Bediş karikatürü 


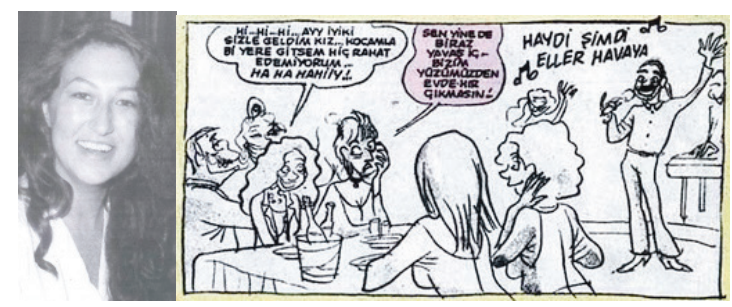

Gülay Batur'dan bir karikatür

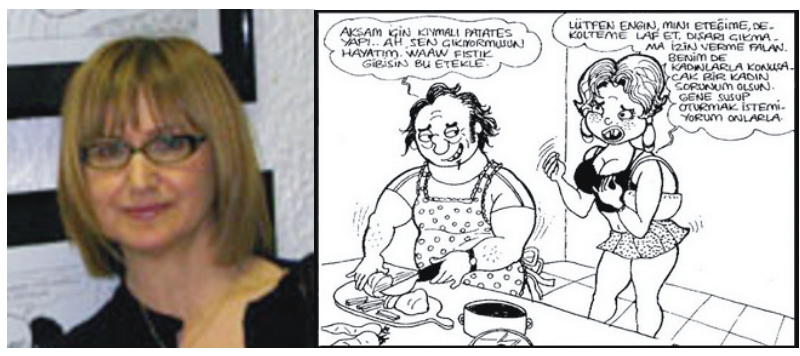

Ramize Erer'den bir karikatür

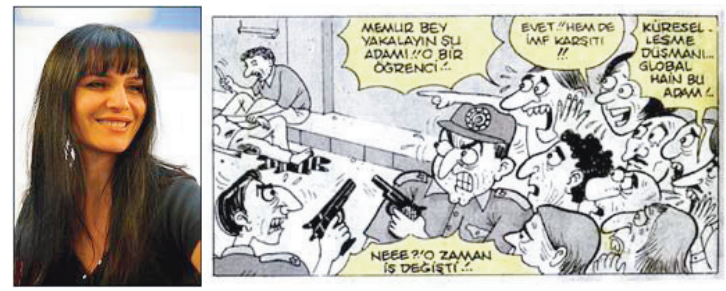

Meral Onat'tan bir karikatür

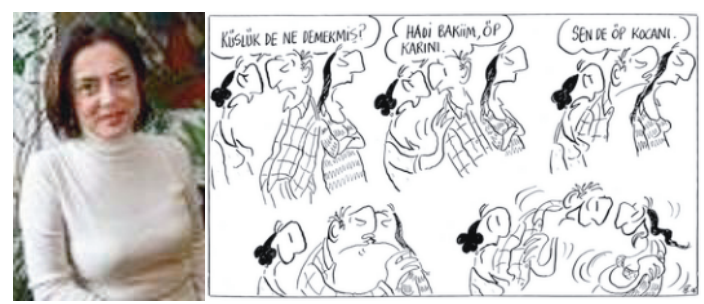

Piyale Madra'dan Ademler ve Havvalar

Piyale Madra ve Nuray Çiftçi de farklı çizgileriyle öne çıkan kadın karikatürcülerdendir. Yalın çizgileri ve kadına farklı açıdan bakışlarıyla diğerlerinden ayrılırlar. Piyale Madra, kadın erkek ilişkilerini psikolojik yönden ele alırken toplum ve birey çatışmalarını öne çıkarır. Öte yandan bireyin içsel çelişkilerini de ortaya koyar.

Nuray Çiftçi, Bulut Bebek bant karikatürüyle çocuğun iç dünyasını yansıtırken anne çocuk girişikliğini ele alır. Diğer bir deyişle kadının ve toplumun sorunlarını çocuk üzerinden verir. Ayrıca reklam amaçlı karikatürler de çizer. 

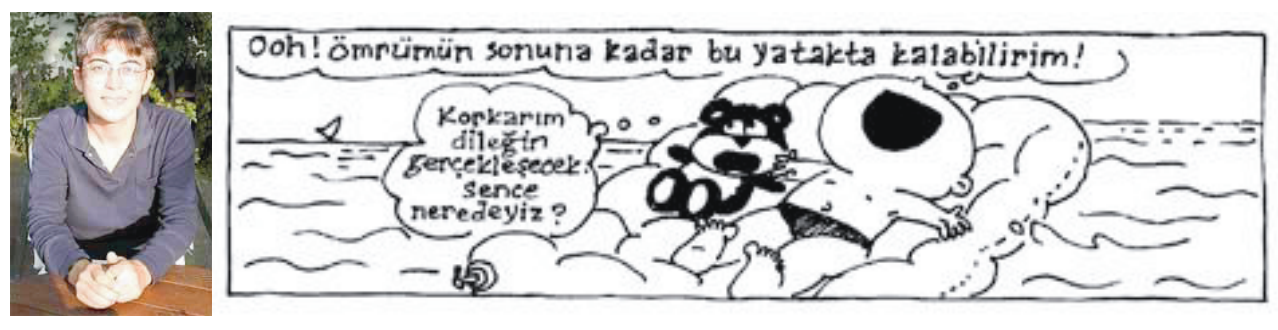

Nuray Çitçi'den Bulut Bebek

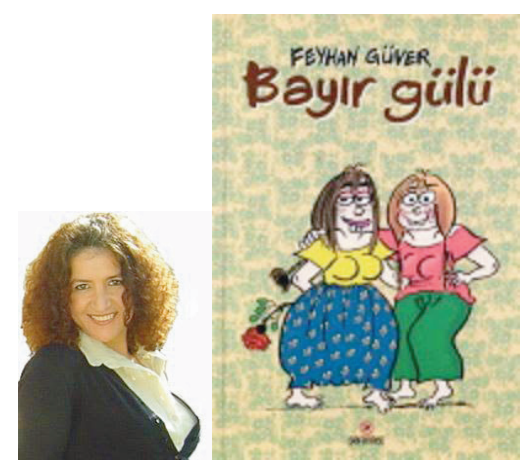

Feyhan Güver'den Bayır Gülü

1993 ’te Feyhan Güver Limon' da çizmeye başlar. Bu süreç Leman, Pazartesi dergileri ile Yeni Binyıl gazetesinde devam eder. Güver, kırsal kesimde yaşayan kadınların sorunlarını dile getiren Bayır Gülü tiplemesiyle adından söz ettirir.

Günlük gazete ve mizah dergilerinin dışında kalan kadın çizerlerin çalışmaları değişik sanat, bilim ve kültür ağırlıklı karikatür albümü, gazete ya da dergilerin yanı sıra karma bireysel karikatür sergilerinde yer almaktadırlar.Bunlardan bazıları; Menekşe Çam, Saadet Yalçın, Zeynep Gargi, Ayten Köse, Tolga Sakarya...

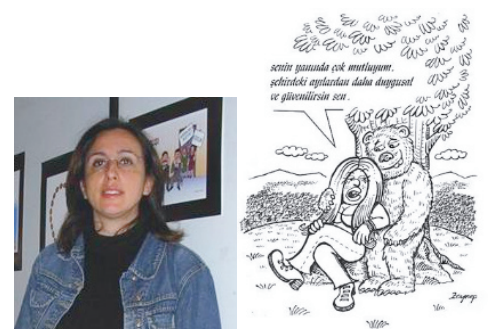

Zeynep Gargi'den bir karikatür

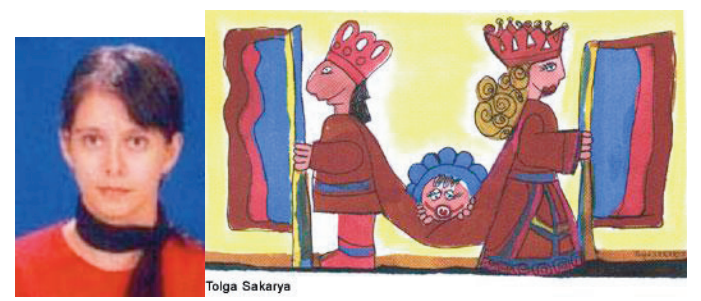

Tolga Sakarya'dan bir karikatür 


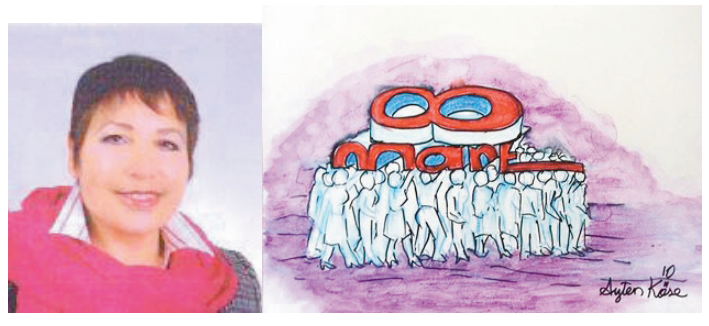

Ayten Köse'den bir karikatür

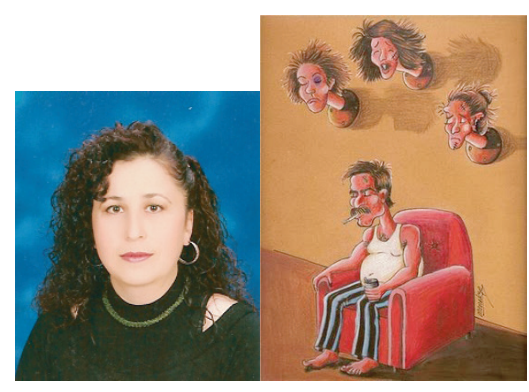

Menekşe Çam'dan bir karikatür

Yukarıda belirtilen grupların dışında kalan ve yoğun bir karikatür çalışması içinde olmayan resim, desen, grafik, vb çalışmaların yanında karikatür de çizen ya da daha karikatür alanına yeni adım atan çizerler de görülmektedir. Sözü edilen kadın çizerlerden bazıları; Tülay Çellek, Melek Okay, Neslihan Özgüven, Hatice Doğan'dır.

Anadolu Karikatürcüler Derneği’nde yer alan kadın karikatürcüler; Irmak Ataberk, Başak Tarım, Derya Duyar, Ebru Keskin, İlkay Saltık.

Kıbrıslı Türk kadın karikatürcüler de şunlardır;Semra Yalçın [1981 - 1983 “Birlik” Gazetesi], Zuhal Denizci [1983 - 1985 "Yeni Düzen”, “Ortam”, "Londra Toplum Postası"], Sevcan Çerkez [2000 - 2008 "Yeni Düzen”, “Ortam”, "Yeni Düzen Sanat”], Elif Atamaz Aşıcıŏlu [2000 - 2001 "Kıbrıs"]

Diğer kadın karikatürcüler; Andaç Gürsoy, Aslı Yazıcıŏlu, Asuman Ercan, Asuman Küçük Kantarcı, Eda Karaabdurrahmanoğlu, (Gırgır çizeri imzasını Eda olarak atıyor. Eda Oral ile karıştırılmamalı.), Esin Özbek, Gülsen Özbey, İpek Özsüslü, Melike Acar, Nermin Er,Nermin Özkan, Neşe Binark, Nilay Kortek, Semra Can, Sumru Ekşioğlu.

Türk karikatüründe kadının etken olduğu söylenemez. Erkek egemen bir toplumda kadının edilgenleştirilmesi, kadın karikatürcüleri de etkiler. Bu olumsuzluk bazı kadın çizerlerimiz tarafından şöyle dile getirilir.

Piyale Madra'nın şu sözleri ilginçtir.“Toplumumuzda kadın, ikinci sınıf vatandaş olarak görülür. Özellikle ataerkil ailelerde çoğunlukla kadının erkeklerin yanında konuşması, hatta gülmesi büyük ayıp olarak görülür. Böyle bir toplumda kadın çizerlerin güldürmeye ve düşündürmeye dayalı bu meslekte sayıca az olmaları çok doğaldır.” Ramize Erer kadın çizer olmanın sıkıntısını şöyle dile getirir.“...Kadınlar da çizsin zenginlik olsun diye düşündüler. Biraz garnitür olarak baktılar bize...” 
Gülay Batur da kadın karikatürcünün az olma gerekçesini aşağıdaki tümcelerle aktarır okura, “Türkiye'de bir tek 'ev kadını' çok fazla zaten. Kadın pilot, kadın şoför vs. neden çok azsa 'kadın karikatürcü' de benzer nedenlerden dolayı çok az..." Ülkemizdeki kadın karikatürcü sayısının artması ülkenin diğer sorunlarının çözümüne bağlıdır, dense de bu pek inandırıcı olmasa gerek. Erkek egemen güçlerin binlerce yılda oluşturduğu bir kültür geleneğinin etkisini göz ardı etmek pek olası değildir. Bu güç, gelecekte kadın karikatürcülerde istenilen niceliğin artmasında büyük bir engeldir. Sonuçta böyle olumsuz bir çevrimin kırılıp açılması salt kadın bakışıla değil, kadın erkek birlikteliğinin oluşturduğu özgürlükler ortamıyla söz konusu olabilir (Efe, 2010).

Feyhan Güver'e çalışma hazırlanırken gönderilen elektronik postada sorulan, Türkiye'de yeterince bayan karikatürist yetişmiyor. Bunun sebebi olarak ne görüyorsunuz? sorusunu, Güver; "Batı sanatı olmasına rağmen ilginçtir ki Türkiye'de hiçbir batı ülkesinde olmadığı kadar çok kadın çizer vardır. Yine de az diyorsak belki bunu geleneklerle ilişkilendirebiliriz. Bir gelenek olarak "kadın çizer" oturmamış bir meslek dalıdır. Kimse çocuğunu "çizer" yapmak için özel çaba harcamaz mesela." şeklinde cevaplamıştır.

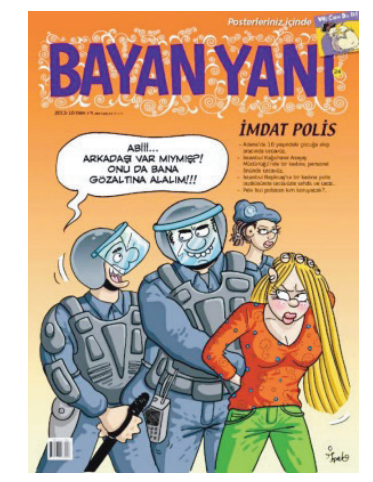

Bayan Yanı Dergisinin 23. Sayıs

Kadın karikatüristler tarafından hazırlanan ve yayımlanan Bayan Yanı dergisinden de bahsetmek gerekmektedir. İlk sayısı 8 Mart 2011 tarihinde yayımlanan dergi çalışma hazırlanırken, 10Ekim 2013 tarihinde 23. sayısını okuyucusu ile buluşturma başarısını göstermiştir.

Genel olarak dünyanın birçok ülkesinde kadar kadın karikatürist sayısı az olsa da ülkemizdeki kadın karikatürist sayısı birçok gelişmiş ülkeden fazladır. Feyhan Güver, çizer olarak çalıştı̆̆ 1 ve sadece kadınların çıkardığı mizah dergisi "BAYAN YANI" adlı dergiden bahsederken, ilk sayının “8 MART” özel sayısı olarak çıktığını, ilgi çekince devamının geldiğini belirtmiştir. Bu tür şeylerin "ihtiyaç" tan çok istemekle olduğunu, karşılık bulmasının da önemli olduğunu, umulmadık bir ilgi olduğu için devam kararı alındığını belirtmiştir. Derginin dünyada bir ilk olduğunu belitmiş, yazıda daha öncede adı geçmiş olan ve Osmanlı döneminde kadınların hazırladığ "LEYLAK" isimli mizah dergisinden de bahsetmiştir. Güver, derginin ilginç olduğunu, 28 Mayıs 1914'te çıkmış olan ilk sayının 8 sayfadan oluştuğunu ve 15 günde bir yayımlandığını belirtmiştir. Ayrıca derginin sadece üç ay çıkabilmiş olmasına karşın inanılmaz bir girişim olduğundan bahsetmiştir.

Feyhan Güver şu anda yayımlanmakta olan Bayan Yanı dergisinden bahsederken de "Umduğumuzdan iyi bir ilgi oldu. Okurlar dergiyi sahiplendiler. Uzun vadeli bir planımız yok. İlgi olduğu sürece çizeceğiz. Derginin ayakta kalabilmesi için maddi olarak kendini finanse etmesi lazım. Bunun yanında tabiiki bir de çizerlerin hevesine ihtiyaç var." demektedir. 
Birçok kesime göre kadın ressamlar ve kadın karikatüristler yeterli yeteneğe sahip değildir. Böyle bir iddiada bulunmak hem yersiz hem de yanlıştır. Bursa Osmangazi ilçesinde yer alan Barbaros Ortaokulu'nda 2012 / 2013 eğitim öğretim y1lında Görsel Sanatlar dersinde yer alan "Değimlerden Karikatürler" etkinliğinde ortaya konulan çalışmalarda genel olarak kız öğrencilerin hem düşünce, hem mizah hem de çizgi yönünden oldukça başarılı oldukları görülmektedir. Buradaki amaç kız öğrencilerin erkek öğrencilerden daha başarılı olduğunu ortaya koymak değildir. Ortaya konulmak istenen; kız öğrencilerin çizgi, mizah ve düşünce olarak erkek öğrencilerden daha düşük seviyede olmadığını ortaya koymaktır.

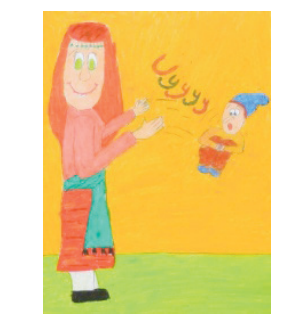

Rumeysa Kasapoğlu Temel Atmak

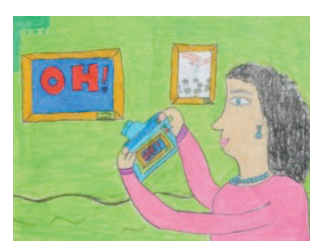

Büşra Işılkcan

Oh Çekmek

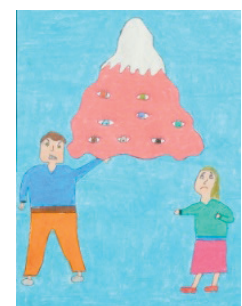

Zeynep Arda

Göz Dă̆ Vermek

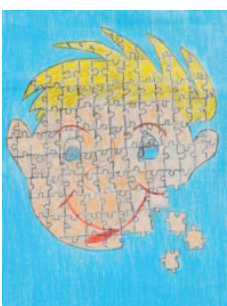

Naciye Şengül

Yüzünden Düşen Bin

Parça

\section{Sonuçlar}

Nüfusu 75 milyonu aşan ve yarısı kadınlardan oluşan ülkemizde kadın karikatürist sayısı ile erkek karikatürist sayısı karşılaştırıldığında oranların birbirine eşit olmadığı görülmektedir. Ayrıca ülkemizdeki kadın karikatüristlerin sayısı gelişmiş birçok ülkeden daha fazladır. Bunun yanında ülkemizde yetişmiş olan kadın karikatüristler dünya karikatür sanatına öncülük etmişlerdir. Bunlara en iyi örnekler dünyada ilk olarak çıkmış olan ve kadın karikatüristler tarafından hazırlanan Leylak dergisi ile halen yayın hayatını devam ettiren Bayan Yanı dergisidir.

\section{Öneriler}

Ülkemizde karikatüre yönelik eğitim veren eğitim kurumları çok azdır. Eğitimler konusunda uzmanlaşmış karikatür ustalarının atölye çalışmalarından ileriye gitmemektedir. Ülkemizde kadın karikatüristlerin sayısının artması için küçük yaştan itibaren eğitim kurumlarında karikatür sanatına yönelik çalışmalar yapılmalıdır. Özellikle kız öğrencilerkarikatür sanatı ile tanışmalı ve ürünler ortaya koymaları konusunda teşvik edilmelidir. Karikatür tarihinde ön plana çıkmış kadın karikatüristlerin yapmış olduğu örnekler gösterilerek cesaretlendirilmelidirler. Şartlar uygun olduğu takdirde bayan karikatüristler okullara davet edilmeli, meslekleri ile ilgili bilgileri öğrencilere aktarmalıdırlar. 


\section{Kaynakça}

Balcıŏlu, S. (1983). Cumhuriyet dönemi Türk karikatürü. Ankara: Türkiye İş Bankası Kültür Yayınları.

Balcığlu, S. (1998). Cumhuriyet’in 75. yllında Türk karikatürü. Ankara: Türkiye İş Bankası Kültür Yayınları.

Çeviker, T. (1988). Gelişim sürecinde Türk karikatürü, 1,2,3. İstanbul: Adam Yayınları.

Efe, H. (2010). Türk karikatüründe kadına genel bakış. Kar Yazın Sanat Kültür Dergisi

Farthing, S. (2012). Sanatın tüm öyküsü. İstanbul: Hayalperest Yayınevi

Özer, A. (1994). İletişim çizgi dili karikatür. Eskişehir: Anadolu Üniversitesi Yayınları

Sipahi, İ. ,Hayatseven, H. İ. (2006). Kadın ve mizah: Kadın karikatüristler (Kadın Eserleri Kütüphanesi Ve Bilgi Merkezi Vakfi 2007 Ajandası). İstanbul: Hanlar Matbaacılık.

Topuz, H. (1997). Başlangıçtan bugüne dünya karikatürü. İstanbul: İnkılap Kitapevi.

Ulusoy, D. (1999). Plastik Sanatlarda Toplumsal Cinsiyet. Hacettepe Üniversitesi Edebiyat Fakültesi Dergisi, c.16 S.2/ss. 47-73.

Uslu, A. (2007). Karikatürün eğitim kaygısı. Bilim ve Aklın Aydınlığında Eğitim Dergisi, 84, 36.

Yolcu, E. (2004). Sanat eğitimi kuramları ve yöntemleri. Ankara: Nobel yayın dağıtım.

www.milliyet.com.tr/Yasam/HaberDetay.aspx?aType=HaberDetay\&KategoriID=5\&ArticleID=1114865\&Date $=07.07 .2009 \& \mathrm{~b}=$ Magara\%20resimlerini\%20disi\%20kuslar\%20yapmis

Çeviker, 2013, http://www.sahirabaci.com/sahirabaci/pages/posts/kadin-mizah-40.php, 30.10.2013'de erişildi. 